International Journal of Engineering \& Technology, $7(3.34)(2018) 491-492$
International Journal of Engineering \& Technology
SPC
Website $:$ www.sciencepubco.com/index.php/IJET
Research paper

\title{
Blindness and Social Media in India
}

\author{
${ }^{1}$ Soumya Thankam Varghese, ${ }^{2}$ Dr.Maya Rathnasabapathy \\ ${ }^{I}$ Research Scholar \\ School of Social Sciences, Vellore Institute of Technology - Chennai Campus, \\ Tamil Nadu, India, Email-Soumya.thankam2017@vitstudent.ac.in \\ ${ }^{2}$ Research Guide \\ School of Social Sciences, Vellore Institute of Technology - Chennai Campus, \\ Tamil Nadu, India
}

\begin{abstract}
In the present world, social networking sites offer a great platform to communicate, collaborate and socialize - personally and professionally with the world around us. According to WHO report, blind people are a significant group comprising 45 million totally blind and 285 million partially blind. This paper reviewing studies on the non (use) of social media by blind people in and out India. It examines the impediments, achievements and expectations of blind people with regard to social network sites based on past research work.
\end{abstract}

Keywords:Visual impairment, blindness, social media

\section{Introduction}

Human interactions are more technically oriented and also technical in its nature these days. Technical revolution in social communication is due to the wide popularity of social networking sites. Even though the popularity of social media among physically challenged people is a negligible area in recent researches on advanced communication and technology operations. Research reviews on blind people's usage on social medias like Twitter and Facebook shows that though the visually impaired people post many things related to them or their favorite things in life, the visual data like photos or videos are comparatively less (Shanomei and Luda, 2014).The mode of communication has been changes rapidly though the development of technological advancements and implementations. The social interactions are the main base for various realms of human interaction is an attractive theme and when it comes to disabled people become more relevant innature. The paper deals with various aspects of visual content and its relevance in communication behavior of visually impaired people of India.

\section{Visual Impairment and Social Media}

The theory of homophily supports the fact that visually impaired or blind people could make strong bonds between or among them and they love to be connected with each other. Like sighted visually impaired people are engaging with social media. The motivational pushes are same as social interaction and fellowship. How do they do that? It is through the accessibility technologies only. Many kinds of reader soft wares are available to help them with the content on the screen. Navigating in social networking sites through mobile or desktops are not a tough job and the review studies shows that more than half a majority of the people are using social networking sites with the help of these technologies. Keyboard navigation shortcuts are another helpful action for them to deal with social networking sites. Unfortunately many more strategies are needed to implement in order to make their technically oriented life much more easy going.

\section{Visual Content on Social Media}

Advances in Artificial Intelligences help the technology to create images as per the descriptions. Visually impaired people who have experienced difficulties with the content of social media can be easily moved on with these technological difficult (Shanomei and Luda, 2014). Ability to explore the visual content naturally motivates them to be connected with the social media in higher degree. Research work on how the visual content affects visually impaired people shows that fear and anxiety plays a good role in their decision making process. Whether a comment or caption goes wrong is the primary concern followed by if it is go wrong what will be the implication on their relationships and interactions on social media life (Voykinska et al, 2016).

When reviewing these studies another important question arises on how they evaluate the visual content posted by people around them. When visual content is quantitatively less means qualitatively high interaction for visually impaired people. Recent announcement of Facebook on "automatic alternative text" created by J. Wieland makes the impossible possible. Where machine learning joints with artificial intelligence and it makes people able to understand or recognize objects. The primary way of interaction for visually impaired people were scree reader software where whatever comes on the screen described by the software for their easy interaction. But the Facebook accessibility team has gone far beyond to make the life of visually impaired easier one. Voykinska et al conducted interviews with visually impaired people particularly about their experiences with social networking sites. $100 \%$ of people were reported that they were quite comfortable with Facebook compared to other social networking sites. 


\section{Visual Content and Challenges}

Buzzi et al (2010) conducted study on accessibility difficulties among visually impaired people and found that screen reader software makes them read the entire page rather than scanning the web page overall for their goal. In social networking sites the alignment of a page also creates difficulties for the visually impaired as some pages will be horizontally and vertically aligned matters on them. Here the reading process becomes more confusing and tension creating for them. Same study they found that the final help on which them rests are sighted people whom they can trusts only. They get help from their closed sighted people in order to address accessibility issues. This is the era of millennials where they explore themselves and others through selfies. Taking or posting pictures are a way of significant communication that you or we are special. Responding to the visual content is so inevitable and essential to keep the relationship or interaction more active and positive. So not responding to the visual contents of social networking sites or describing the visual content in a not appealing way could make them more tensed as they are more concerned with the output of their interactions. Java Script usage also creates tension among visually impaired in terms of focusing and reproducing the contents of social media. Social networking sites are playing different layers of interaction these days. It is a platform for expressing and exchanging our view points and also serves as a means for propagating information among society. Apart from Facebook, Twitter we could take Whatsapp too. Whatsappoption for sending audio messages is a better option for the visually impaired people. It'seasier and not compromising with the quality of audio too. The reviews studies found that many of the researches go around Facebook and Twitter alone. Reaching any conclusive statement is more difficult as they are limited on these two prominent social networking sites. Studies which focus on more different kind of social networking sites and mode of interaction need to be analyzed to get much more clarification.

\section{Visual Content and Future Expectations}

The developments in assistive technologies and voice input already taken out and minimized the challenges or barriers for visually impaired people. The review studies shows that more changes needed on the content analysis part as the visually impaired people are getting more stuck with production or reproduction of content on social networking sites. More technological aid for auto detection of content accuracy and responses are needed in this regard. Now the technological progresses on Artificial Intelligence helped them or us to overcome many challenges and people are able to recognize the visual content through auto detection abled software designs. The blind and visually impaired are a significant population in the world as the number goes around 39 million globally (WHO, 2013).More interdisciplinary and qualitative approaches are needed to understand accessibility and usability options about social networking sites. Challenges they are facing during their involvement with social networking sites can be listed as time, the extent of effort and accessibility problems. Towards what extent they could utilize the options given in the websites such as event creation etc. raises question about how much user friendly it is.

\section{Conclusion}

However the technology developments have been reached the middle or high level economic group and the low income group stays away from all these kinds of development. Here though the accessibility of the technology won't raise any concern to us, but how much or to what extent they are affordable is a significant question in the social set up of India. The research on social networking sites should consider how much they can reach to the needed population regardless of their socio-economic status. The central aspect of this review is that we have to go a long way to overcome these accessibility barriers to make the social networking site more intractable and convenient for them.

\section{References}

[1] Shaomei Wu., Lada A. Adamic. (2014). Visually Impaired Users on an OnlineSocial Network.In Proceedings of the SIGCHI Conference on Human Factors in Computing Systems (CHI '14), 3133-3142.https://doi.org/10.1145/2556288.2557415

[2] Violeta Voykinska, Shiri Azenkot, Shaomei Wu, and Gilly Leshed. 2016. How Blind People Interact with Visual Content on Social Networking Services. In Proceedings of the 19th ACM Conference on Computer- Supported Cooperative Work \& Social Computing (CSCW '16), 1584-1595.https://doi.org/10.1145/2818048.2820013

[3] Buzzi, M.C., Buzzi, M., Leporini, B., and Akhter, F.(2010). Is Facebook really "open" to all? International Symposium on Technology andSociety, Proceedings, IEEE, 327-336.Symposium on Technology and Society (ISTAS), NSW, 327-36.

[4] World Health Organization, "Visual impairment and blindness," WHO.int, October 2013. 